Article

\title{
One-Pot Multi-Enzymatic Production of Purine Derivatives with Application in Pharmaceutical and Food Industry
}

\author{
Javier Acosta ${ }^{1}$, Jon del Arco ${ }^{1}$, Sara Martinez-Pascual ${ }^{1}$, Vicente Javier Clemente-Suárez ${ }^{1,2}$ and \\ Jesús Fernández-Lucas ${ }^{1,2, *}$ \\ 1 Applied Biotechnology Group, European University of Madrid, c/ Tajo s/n, Villaviciosa de Odón, \\ Madrid 28670, Spain; jacosta19.ja97@gmail.com (J.A.); jondelarco@gmail.com (J.d.A.); \\ sara.mp.94@gmail.com (S.M.-P.); vicentejavier.clemente@universidadeuropea.es (V.J.C.-S.) \\ 2 Grupo de Investigación en Desarrollo Agroindustrial Sostenible, Universidad de la Costa, CUC, \\ Calle 58 \# 55-66, Barranquilla 080002, Colombia \\ * Correspondence: jesus.fernandez2@universidadeuropea.es; Tel.: +34-91-211-5147
}

Received: 30 November 2017; Accepted: 28 December 2017; Published: 1 January 2018

\begin{abstract}
Biocatalysis reproduce nature's synthetic strategies in order to synthesize different organic compounds. Natural metabolic pathways usually involve complex networks to support cellular growth and survival. In this regard, multi-enzymatic systems are valuable tools for the production of a wide variety of organic compounds. Methods: The production of different purine nucleosides and nucleoside-5'-monophosphates has been performed for first time, catalyzed by the sequential action of 2'-deoxyribosyltransferase from Lactobacillus delbrueckii ( $L d N D T$ ) and hypoxanthine-guanine-xanthine phosphoribosyltransferase from Thermus themophilus HB8 (TtHGXPRT). Results: The biochemical characterization of $L d \mathrm{NDT}$ reveals that the enzyme is active and stable in a broad range of $\mathrm{pH}$, temperature, and ionic strength. Substrate specificity studies showed a high promiscuity in the recognition of purine analogues. Finally, the enzymatic production of different purine derivatives was performed to evaluate the efficiency of multi-enzymatic system $L d \mathrm{NDT} / \mathrm{TtHGXPRT}$. Conclusions: The production of different therapeutic purine nucleosides was efficiently catalyzed by $L d \mathrm{NDT} / \mathrm{TtHGXPRT}$. In addition, the resulting by-products were converted to IMP and GMP. Taking all of these features, this bioprocess entails an efficient, sustainable, and economical alternative to chemical synthetic methods.
\end{abstract}

Keywords: 2'-deoxyribosyltransferase; phosphoribosyltransferases; cascade reactions; purine nucleoside analogues; dietary nucleotides

\section{Introduction}

Nucleoside analogues, NAs, form a very large family of compounds, with more than 40 presently used in medicine as antiviral and anticancer agents [1,2]. Actually, a variety of therapeutic nucleosides and nucleotides, which are in the WHO "List of essential medicines" are produced chemically, such as Abacavir (HIV therapeutic), Capecitabine (anticancer), Cytarabine (anticancer, antiviral), Vidarabine (antiviral), or Floxuridine (anticancer), among others. Due to the economic and social relevance of these kind of drugs, the availability of a stereo-selective and cheap synthetic method is relevant for the industry and developing countries.

Furthermore, nucleoside- 5 -monophosphates, NMPs, are often used as food additives or intermediates by the pharmaceutical industry. For example, some dietary nucleotides, such as inosinic acid (inosine-5'-monophosphate, IMP) or guanosinic acid (guanosine-5'-monophosphate, GMP), are common additives used as flavour enhancers in foods, since they induce an umami taste 
sensation [3]. As a result, current demand for nucleotides in the food additives market is increasing, and the production of nucleotides has been widely studied.

NAs and NMPs have been traditionally synthesized by chemical methods through multistep processes requiring protection and de-protection steps for the labile groups, and isolation in almost every step due to the poor regio- or stereoselectivity of the reactions [4-8]. These drawbacks lead to a high price of these valuable compounds, limiting their application.

Nowadays, the application of bioprocesses that are catalyzed by whole cells or enzymes in industry is gaining ground against traditional chemical synthetic processes. In this context, the enzymatic synthesis of NAs and NMPs shows many advantages, such as one-pot reactions under mild conditions, high stereo-, and regioselectivity, and an environmentally friendly technology [4-11].

Purine metabolism is a metabolic route of vital importance in all the living organisms, since purines are essential for the synthesis of nucleic acids (DNA and RNA), proteins, and other metabolites. In the de novo pathway cells use simple precursors like glycine, glutamine, or aspartate for the synthesis of the different purine nucleotides. On the contrary, the salvage pathway is composed by a group of reutilization routes by which the cell can satisfy its purine requirements from endogenous and/or exogenous sources of preformed purines. In this regard, numerous enzymes from purine salvage pathway have become valuable catalysts for mono or multi-enzymatic synthesis of nucleosides and nucleotides, such as nucleoside kinases (NKs) [12-15], phosphoribosyltransferases [7,9-11], nucleoside phosphorylases [4,8,16,17], 2'-deoxyribosyltransferases [5,18-20], among others.

The use of multi-enzymatic systems in organic synthesis offers several advantages, such as the realization of more complex synthetic schemes, the ability to make reversible processes irreversible, to shift the equilibrium reaction in desired way, and the partial or total elimination of product inhibition problems or the prevention of the shortage of substrates by dilution or degradation in the bulk media [13]. In this regard, the aim of this work is the development of a novel multi-enzymatic system for the industrial production of different NAs and NMPs with application in pharmaceutical and food industry. To achieve this objective, an in vitro multienzymatic system composed by 2'-deoxyribosyltransferase from Lactobacillus delbrueckii (LdNDT) and the hypoxanthine-guanine-xanthine phosphoribosyltransferase from Thermus themophilus HB8 (TtHGXPRT), is developed. As shown in Figure 1, the sequential action of LdNDT and hypoxanthine-guanine-xanthine TtHGXPRT can efficiently catalyze the synthesis of NAs and NMPs in two steps.

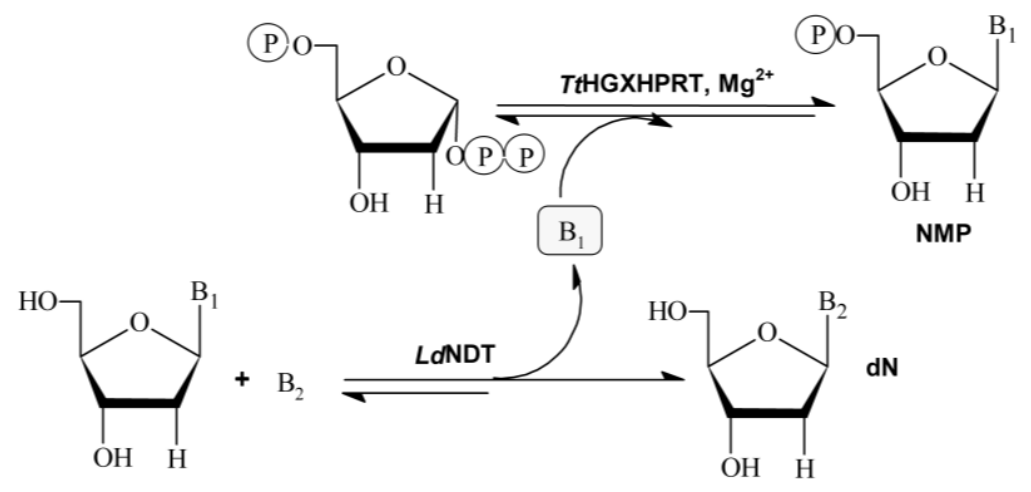

Figure 1. Multi-enzymatic system $L d N D T / T t H G X P R T . B_{1}$ and $B_{2}$ : Purine bases; $d N$ : 2'-deoxynucleoside; NMP: nucleoside-5'-monoposphate.

Nucleoside 2'-deoxyribosyltransferases (NDTs, E.C. 2.4.2.6) catalyze the transglycosylation reaction between a 2'-deoxynucleoside donor and a nucleobase acceptor. According to their substrate specificity, NDTs can be classified into two classes: type I (PDT), specific for purines (Pur $\leftrightarrow$ Pur), and type II (NDT), which catalyze the transfer between purines and/or pyrimidines (Pur $\leftrightarrow \mathrm{Pur}, \mathrm{Pur} \leftrightarrow \mathrm{Pyr}$, Pyr $\leftrightarrow$ Pyr) $[5,19,20]$ (Figure 1). 
Purine and pyrimidine phosphoribosyltransferases (PRTs) catalyze the reversible transfer of the 5-phosphoribosyl group from 5-phospho- $\alpha$-D-ribosyl-1-pyrophosphate (PRPP) to purine and pyrimidine nucleobases or derivatives in the presence of $\mathrm{Mg}^{2+}$ (Figure 1).

The coupled system $L d N D T / T t H G X P R T$ allowed for the enzymatic production of different NAs by transglycosilation reaction using 2'-deoxynosine or 2'-deoxyguanosine as donors, and different modified purine nucleobases as acceptors. Interestingly, TtHGXPRT can slightly shift the equilibrium reaction of the NDT-catalyzed transglycosylation reaction in desired way, and partially eliminate undesired by-products (hypoxanthine or guanine) from bulk-media using PRTs to synthesize highly valuable nucleoside- $5^{\prime}$-monophosphates (NMPs), commercially available as food additives (IMP or GMP).

\section{Results}

\subsection{Production, Purification and Substrate Specificity of Recombinant LdNDT}

The $n d t$ gene, encoding a 2'-deoxyribosyltransferase from Lactobacillus delbrueckii, was cloned and over-expressed in E. coli BL21 (DE3), as described above. The recombinant N-terminal His6-tagged $L d$ NDT was purified using affinity chromatography. After this process, N-terminal His6-tagged was removed from $L d N D T$ using thrombin to avoid precipitation of the protein. To classify our recombinant protein, we carried out the enzymatic synthesis of nucleosides using different riboand $2^{\prime}$-deoxyribonucleosides as donors and several purine and pyrimidine bases as acceptors (Table 1). In this regard, uridine (Uri), adenosine (Ado), cytdine (Cyd), 2'-deoxyadenosine (dAdo), 2'-deoxyuridine (dUri), 2'-deoxycytidine (dCyd), thymidine (dThd), 2'-deoxyinosine (dIno) and $2^{\prime}$-deoxyguanosine (dGuo) were tested as donors, and adenine (Ade), uracil (Ura), cytosine (Cyt), thymine (Thy) and hypoxanthine (Hyp) were used as acceptors. LdNDT did not show any activity on Uri, Cyd and Ado (data not shown). LdNDT is type II NDT, active over purine and pyrimidine 2'-deoxynucleosides and bases with a strong preference for $\mathrm{dCyd}$ and dUrd as best donors, followed by Thd. In turn, the most and least preferred acceptors are Ade, Cyt and Ura.

Table 1. Substrate specificity of $L d$ NDT upon synthesis of natural nucleosides.

\begin{tabular}{cccccc}
\hline \multirow{2}{*}{ Acceptor } & \multicolumn{5}{c}{ Specific Activity (IU/mg Protein) } \\
\cline { 2 - 6 } Donor & Ade & Ura & Cyt & Thy & Hyp \\
\hline dAdo & - & $43 \pm 5$ & $83 \pm 8$ & $45 \pm 2$ & $7.5 \pm 1$ \\
dUrd & $187 \pm 2$ & - & $165 \pm 6$ & $135 \pm 5$ & $106 \pm 7$ \\
dCyd & $189 \pm 7$ & $104 \pm 6$ & - & $48 \pm 8$ & $101 \pm 8$ \\
Thd & $101 \pm 4$ & $113 \pm 3$ & $113 \pm 6$ & - & $88 \pm 8$ \\
dIno & $22 \pm 8$ & $40 \pm 4$ & $64 \pm 7$ & $40 \pm 0$ & - \\
dGua & $116 \pm 9$ & $54 \pm 4$ & $80 \pm 2$ & $22 \pm 4$ & $20 \pm 3$ \\
\hline
\end{tabular}

Reaction conditions: $0.3 \mu \mathrm{g}$ of enzyme were incubated at $50^{\circ} \mathrm{C}$ and and $300 \mathrm{rpm}$ for $5 \mathrm{~min}$ with $10 \mathrm{mM}$ substrates in $50 \mathrm{mM}$ MES buffer, $\mathrm{pH} 6.5$ in a final volume of $40 \mu \mathrm{L}$.

\subsection{Biochemical Characterization of LdNDT}

The effects of temperature, $\mathrm{pH}$, and ionic strength on the stability and activity of the enzyme were studied to determine the optimal operational conditions of the enzyme (Figure 2). The $\mathrm{pH}$ profile revealed that $L d$ NDT displays optimal activity in the $\mathrm{pH}$ range 6-7, with maximum activity in $50 \mathrm{mM}$ phosphate pH 6.0 (Figure 2a). As shown in Figure 2b, LdNDT displayed high activity (more than $60 \%$ ) across a broad temperature range (from $40^{\circ} \mathrm{C}$ to $70^{\circ} \mathrm{C}$ ), with the maximum activity at $60^{\circ} \mathrm{C}$. In addition, a negligible loss of activity was observed in presence of $500 \mathrm{mM}$ of sodium chloride, and a slight activity decrease was observed when sodium chloride concentration was increased ( $60 \%$ activity remained at $1 \mathrm{M}$ sodium chloride) (Figure 2c). 
(a)

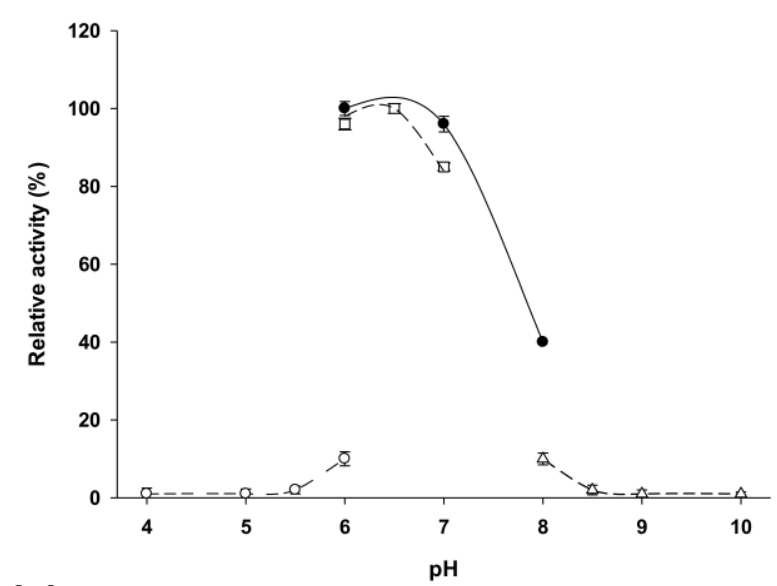

(c)

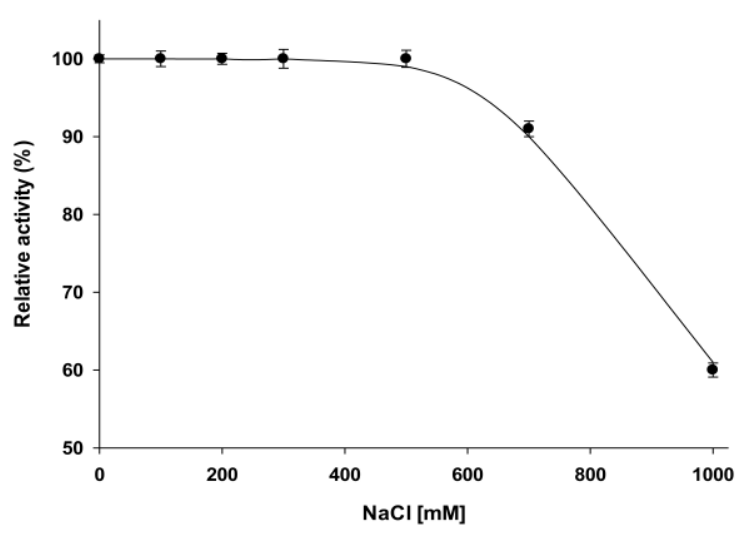

(b)

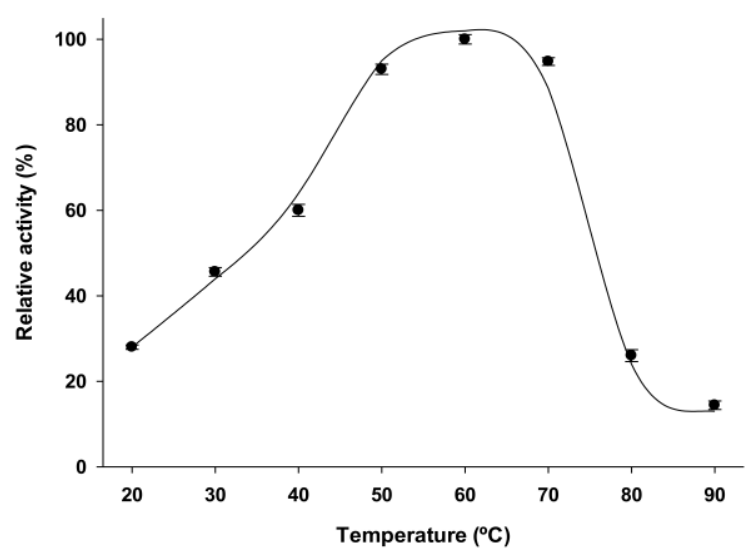

(d)

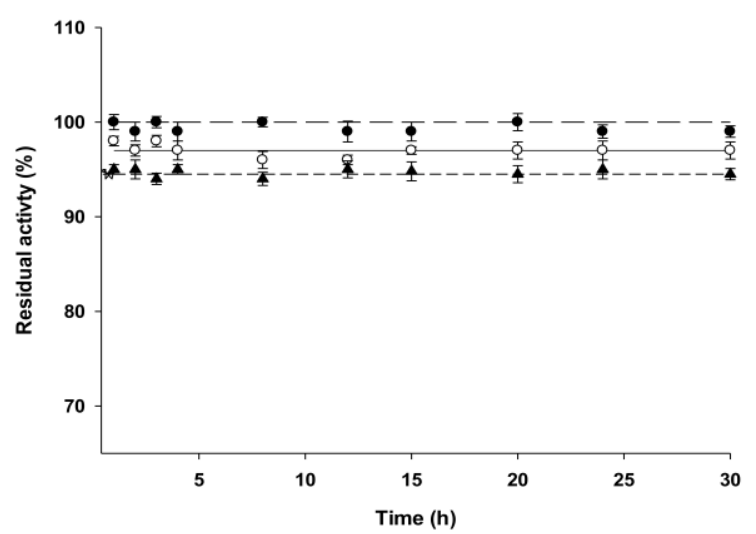

Figure 2. Temperature and $\mathrm{pH}$ dependence on $L d \mathrm{NDT}$ activity and stability. (a) Effect of $\mathrm{pH}$ on $L d \mathrm{NDT}$ activity, (○) sodium acetate $50 \mathrm{mM}$ (pH 4-6), ( $\square$ ) MES $50 \mathrm{mM}$ (pH 6-7), (•) sodium phosphate $50 \mathrm{mM}$ (pH 6-8), ( $\Delta$ ) sodium borate $50 \mathrm{mM}$ (pH 8-10). (b) Effect of temperature on LdNDT activity (•). (c) Effect of ionic strenght on $L d \mathrm{NDT}$ activity (•). (d) Thermal inactivation at $50{ }^{\circ} \mathrm{C}$ of $L d \mathrm{NDT}$ at different $\mathrm{pH}$ values, pH $6(\bullet)$, pH $8.5(\bigcirc)$, and $\mathrm{pH} 10(\mathbf{\Delta})$.

The storage of $L d \mathrm{NDT}$ at $4{ }^{\circ} \mathrm{C}$ was analyzed to ensure biocatalyst stability, and $L d \mathrm{NDT}$ retained its activity more than 150 days (85\% relative activity) (data not shown). LdNDT also displays $90 \%$ of retained activity when is stored at $-20^{\circ} \mathrm{C}$ or $-80^{\circ} \mathrm{C}$. In addition, the effect of $\mathrm{pH}$ on $L d \mathrm{NDT}$ stability was evaluated by incubating the enzyme for $30 \mathrm{~h}$ at $50{ }^{\circ} \mathrm{C}$ at different $\mathrm{pH}$ conditions (ranging from 6.5 to 10). As we can see in Figure $2 \mathrm{~d}$, there was a negligible loss of activity in any case under these experimental conditions.

\subsection{Enzymatic Production of Purine NAs Catalyzed by LdNDT}

In order to explore the potential of $L d N D T$ as an industrial biocatalyst, the enzymatic production of several nucleoside analogues was carried out using different non-natural purine bases under different assay conditions. As we can see in Table 2, $L d N D T$ is able to recognize many different purine analogues, such as 2-fluoroadenine (2-FAde), 2-chloroadenine (2-ClAde), 2,6-diaminourine (2,6-DAP), 6-chloropurine (6-ClPur), 6-mercaptopurine (6-M), 6-methylpurine (6-Met) 6-methoxyguanine (6-MeOGua), 7-deaza-6-hydroxypurine (7-deaza6OHPur), 7-deazaxanthine (7-deazaXan), theophylline (The), benzoyladenine (BenzoA), and xanthine (Xan). 
Table 2. Enzymatic productions of nucleoside analogues from purine base derivatives catalyzed by LdNDT.

\begin{tabular}{cccc}
\hline Donor & Acceptor & Product & Conversion (\%) \\
\hline \multirow{6}{*}{ dIno } & 2-FAde & 2-F-dAdo & $64 \pm 3$ \\
2-ClAde & 2-CldAdo & $34 \pm 1$ \\
2,6-DAP & 2,6-DAPdRib & $81 \pm 0$ \\
& 6-ClPur & 6-ClPurdRib & $70 \pm 3$ \\
& 6-M & 6-MdRib & $9 \pm 2$ \\
& 6-MetPur & 6-MetPurdRib & $51 \pm 4$ \\
& 6-MeOGua & 6-MeOdGuo & $61 \pm 3$ \\
& 7-deaza6OHPur & 7-deaza6OHPurdRib & $4 \pm 0$ \\
& 7-deazaXan & 7-deazadXao & $<1 \pm 0.5$ \\
& The & ThedRib & $17 \pm 3$ \\
& BenzoA & BenzoAdRib & $10 \pm 2$ \\
& Xan & dXao & $15 \pm 3$ \\
\hline
\end{tabular}

Reaction conditions: $0.3 \mu \mathrm{g}$ of enzyme in $40 \mu \mathrm{L}$ at $50{ }^{\circ} \mathrm{C}$ and and $300 \mathrm{rpm}, 20 \mathrm{~min}$. [Substrates] $=1 \mathrm{mM}, 50 \mathrm{mM}$ sodium phosphate buffer, $\mathrm{pH}$ 6.0.

\subsection{Enzymatic Production of Purine NAs and Purine NMPs Catalyzed by Multi-Enzymatic System LdNDT/TtHXGPRT}

With the aim of evaluating an alternative methodology for the synthesis of purine NAs and NMPs, the efficiency of multi-enzymatic system $L d N D T / T t H X G P R T$ was tested. For this purpose, different reactions were performed using dIno or dGuo as nucleoside donor in combination with different purine derivatives as acceptors. After the transglycosilation reaction catalyzed by LdNDT (Reaction 1), the resulting by-products (Hyp or Gua) were converted to IMP or GMP by TtHGXPRT (Reaction 2) (Figure 1).

In order to evaluate the efficiency of this multi-enzymatic system against soluble $L d N D T$, the synthesis of $2^{\prime}$ deoxycytidine ( $\mathrm{dCyd}$ ) has been performed by two different approaches. On the one hand, dCyd has been synthesized from 2'-deoxyguanosine (dGuo) and cytosine (Cyt) by LdNDT at different substrate concentrations of donor $(3 \mathrm{mM}$ and $1 \mathrm{mM})$ and acceptor $(1 \mathrm{mM})$ (Table S1). On the other hand, dCyd was produced under similar conditions in presence of $L d N D T / T t H X G P R T$ (Table S1). As expected, the presence of TtHXGPRT leads to an improvement of conversion in transglycosylation reaction (reaction 1), but there is no a great difference in nucleoside production in presence of $L d N D T / T t H X G P R T$ against soluble $L d N D T$. Interestingly, the ratio 3/1 (donor/acceptor) seems to be the optimal molar ratio between donor and acceptor (Table S1). In addition, in order to know if the presence of phosphate affects the reaction (high phosphate buffers can chelate $\mathrm{Mg}^{2+}$ and decrease the concentration of $\mathrm{Mg}^{2+}$ in reaction medium), authors have tested the transferase reaction (reaction 2) in presence of phosphate buffer and sodium borate buffer, with negligible difference in activity (data not shown).

Taking account of the results, many different nucleoside analogues, such as 2-fluoro-2'-deoxyadenosine (2-F-dAdo), 2-chloro-2'-deoxyadenosine (cladribine, 2-CldAdo), 2,6-diaminopurine-2'-deoxyriboside (2,6-DAPdRib), 6-mercaptopurine-2'-deoxyriboside (6-MdRib), 6-methyl-2'-deoxyriboside (6-MetPurdRib), and 6-methoxy-2'-deoxyguanosine (6-MeOdGuo) have been produced by employing this unprecedented multi-enzymatic system (Table 3 ). 
Table 3. Enzymatic production of nucleoside and nucleotide analogues from purine base derivatives catalyzed by multi-enzymatic system LdNDT/TtHXGPRT (Figure 1).

\begin{tabular}{|c|c|c|c|c|c|c|}
\hline Donor & $\begin{array}{l}\text { Acceptor } \\
\text { Base } 2\end{array}$ & $\begin{array}{l}\text { Product } 1 \\
\text { dN (mM) }\end{array}$ & $\begin{array}{c}\text { Product } 2 \\
\text { NMP (mM) }\end{array}$ & Base $1(\mathrm{mM})$ & $\begin{array}{l}\text { Remaining Acceptor } \\
\text { Base } 2(\mathrm{mM})\end{array}$ & $\begin{array}{c}\text { Remaining } \\
\text { Donor (mM) }\end{array}$ \\
\hline \multirow{6}{*}{ dGuo } & 2-Fade & $\begin{array}{l}\text { 2-F-dAdo } \\
(0.77 \pm 0.04)\end{array}$ & $\begin{array}{c}\text { GMP } \\
(0.15 \pm 0.02)\end{array}$ & $\begin{array}{c}\text { Gua } \\
(0.57 \pm 0.02)\end{array}$ & $\begin{array}{c}\text { 2-Fade } \\
(0.23 \pm 0.05)\end{array}$ & $\begin{array}{c}\text { dGuo } \\
(2.28 \pm 0.02)\end{array}$ \\
\hline & 2-ClAd & $\begin{array}{l}\text { 2-CldAdo } \\
(0.71 \pm 0.02)\end{array}$ & $\begin{array}{c}\text { GMP } \\
(0.15 \pm 0.01)\end{array}$ & $\begin{array}{c}\text { Gua } \\
(0.57 \pm 0.03)\end{array}$ & $\begin{array}{c}\text { 2-ClAde } \\
(0.29 \pm 0.01)\end{array}$ & $\begin{array}{c}\text { dGuo } \\
(2.28 \pm 0.00)\end{array}$ \\
\hline & 2,6-DAP & $\begin{array}{c}\text { 2,6-DAPdRib } \\
(0.85 \pm 0.01)\end{array}$ & $\begin{array}{c}\text { GMP } \\
(0.16 \pm 0.00)\end{array}$ & $\begin{array}{c}\text { Gua } \\
(0.77 \pm 0.05)\end{array}$ & $\begin{array}{c}\text { 2,6-DAP } \\
(0.15 \pm 0.02)\end{array}$ & $\begin{array}{c}\text { dGuo } \\
(2.07 \pm 0.02)\end{array}$ \\
\hline & $6-\mathrm{M}$ & $\begin{array}{c}\text { 6-MdRib } \\
(0.67 \pm 0.02)\end{array}$ & $\begin{array}{c}\text { GMP } \\
(0.35 \pm 0.03)\end{array}$ & $\begin{array}{c}\text { Gua } \\
(0.75 \pm 0.02)\end{array}$ & $\begin{array}{c}\text { 6-M } \\
(0.33 \pm 0.03)\end{array}$ & $\begin{array}{c}\text { dGuo } \\
(1.9 \pm 0.01)\end{array}$ \\
\hline & 6-MetPur & $\begin{array}{l}\text { 6-MetPurdRib } \\
(0.68 \pm 0.05)\end{array}$ & $\begin{array}{c}\text { GMP } \\
(0.15 \pm 0.04)\end{array}$ & $\begin{array}{c}\text { Gua } \\
(0.46 \pm 0.01)\end{array}$ & $\begin{array}{l}\text { 6-MetPur } \\
(0.32 \pm 0.03)\end{array}$ & $\begin{array}{c}\text { dGuo } \\
(2.39 \pm 0.02)\end{array}$ \\
\hline & 6-MeOGua & $\begin{array}{l}\text { 6-MeOdGuo } \\
(1.0 \pm 0.04)\end{array}$ & $\begin{array}{c}\text { GMP } \\
(0.15 \pm 0.04)\end{array}$ & $\begin{array}{c}\text { Gua } \\
(0.95 \pm 0.02)\end{array}$ & $\begin{array}{l}\text { 6-MeOGua } \\
(0)\end{array}$ & $\begin{array}{c}\text { dGuo } \\
(1.9 \pm 0.04)\end{array}$ \\
\hline \multirow{6}{*}{ dIno } & 2-FAde & $\begin{array}{l}\text { 2-F-dAdo } \\
(0.84 \pm 0.00)\end{array}$ & $\begin{array}{c}\text { IMP } \\
(0.1 \pm 0.02)\end{array}$ & $\begin{array}{c}\text { Hyp } \\
(0.74 \pm 0.02)\end{array}$ & $\begin{array}{c}\text { 2-Fade } \\
(0.16 \pm 0.02)\end{array}$ & $\begin{array}{c}\text { dIno } \\
(2.16 \pm 0.02)\end{array}$ \\
\hline & 2-ClAde & $\begin{array}{l}\text { 2-CldAdo } \\
(0.78 \pm 0.01)\end{array}$ & $\begin{array}{c}\text { IMP } \\
(0.12 \pm 0.02)\end{array}$ & $\begin{array}{c}\text { Hyp } \\
(0.77 \pm 0.04)\end{array}$ & $\begin{array}{c}\text { 2-ClAde } \\
(0.22 \pm 0.04)\end{array}$ & $\begin{array}{c}\text { dIno } \\
(2.11 \pm 0.03)\end{array}$ \\
\hline & 2,6-DAP & $\begin{array}{c}\text { 2,6-DAPdRib } \\
(0.79 \pm 0.01)\end{array}$ & $\begin{array}{c}\text { IMP } \\
(0.14 \pm 0.01)\end{array}$ & $\begin{array}{c}\text { Hyp } \\
(0.56 \pm 0.04)\end{array}$ & $\begin{array}{c}2,6 \text {-DAP } \\
(0.21 \pm 0.03)\end{array}$ & $\begin{array}{c}\text { dIno } \\
(2.3 \pm 0.04)\end{array}$ \\
\hline & $6-\mathrm{M}$ & $\begin{array}{l}\text { 6-MdRib } \\
(0.66 \pm 0.00)\end{array}$ & $\begin{array}{c}\text { IMP } \\
(0.24 \pm 0.02)\end{array}$ & $\begin{array}{c}\text { Hyp } \\
(0.46 \pm 0.01)\end{array}$ & $\begin{array}{c}\text { 6-M } \\
(0.34 \pm 0.03)\end{array}$ & $\begin{array}{c}\text { dIno } \\
(2.3 \pm 0.04)\end{array}$ \\
\hline & 6-MetPur & $\begin{array}{l}\text { 6-MetPurdRib } \\
(0.72 \pm 0.05)\end{array}$ & $\begin{array}{c}\text { IMP } \\
(0.13 \pm 0.04)\end{array}$ & $\begin{array}{c}\text { Hyp } \\
(0.66 \pm 0.02)\end{array}$ & $\begin{array}{l}\text { 6-MetPur } \\
(0.28 \pm 0.02)\end{array}$ & $\begin{array}{c}\text { dIno } \\
(2.21 \pm 0.01)\end{array}$ \\
\hline & 6-MeOGua & $\begin{array}{l}\text { 6-MeOdGuo } \\
(1.0 \pm 0.04)\end{array}$ & $\begin{array}{c}\text { IMP } \\
(0.1 \pm 0.00)\end{array}$ & $\begin{array}{c}\text { Hyp } \\
(0.62 \pm 0.00)\end{array}$ & $\begin{array}{l}\text { 6-MeOGua } \\
\text { (0) }\end{array}$ & $\begin{array}{c}\text { dIno } \\
(2.28 \pm 0.02)\end{array}$ \\
\hline
\end{tabular}

Reaction conditions: $0.3 \mu \mathrm{g}$ of $L d \mathrm{NDT}, 1 \mu \mathrm{g}$ of $T t \mathrm{HGXPRT}$ in $40 \mu \mathrm{L}$ at $50^{\circ} \mathrm{C}$ and $300 \mathrm{rpm}, 20-60 \mathrm{~min}$. [dIno] = [dGuo] $=3 \mathrm{mM} ;[$ base $]=1 \mathrm{mM}$, [PRPP] = $1 \mathrm{mM}$, [ $\left.\mathrm{MgCL}_{2}\right]=1.2 \mathrm{mM}$, in $50 \mathrm{mM}$ sodium phosphate buffer, $\mathrm{pH}$ 6.0.

\section{Discussion}

Nucleoside analogues are important molecules used as antiviral and antitumoral drugs [1,2,21], because of their role as inhibitors of the replication of nucleic acids, and can also be employed as starting materials for antisense oligonucleotides. Modified nucleosides have been traditionally synthesized by different chemical methods, requiring the use of protection-deprotection steps, organic solvents and chemical reagents [4-11]. In this sense, $L d N D T$ has shown to be an interesting sustainable alternative to traditional chemical methods for the synthesis of many different purine nucleosides. However, the presence of by-products (nucleobases), or the difficulty to shift the equilibrium of the reaction in desired way, increases production costs, impeding the scale up these processes from laboratory to industry.

Cascades involving enzymes have recently become a thoroughly-investigated field, which offers efficient solutions to circumvent these problems, by removing by-products and leading to shift the reaction towards the formation of products. In this regard, the aim of this work is the development of a new efficient coupled system, which consists in two consecutive reactions catalyzed by $L d$ NDT (Reaction 1) and TtHGXPRT (Reaction 2), which leads to: (i) a more efficient production of 2 -deoxynucleoside analogues due to the shift of the equilibrium of transglycosylation reaction, and (ii) the generation of NMPs with application in food industry.

For this purpose, we describe the production and biochemical characterization of $2^{\prime}$-deoxyribosyltransferase from $L d$ NDT. According substrate specificity studies, $L d N D T$ is a type II NDT, which recognizes both purine and pyrimidine bases and 2'-deoxynucleosides. LdNDT present significant catalytic activity in a broad temperature range (from $40^{\circ} \mathrm{C}$ to $70^{\circ} \mathrm{C}$ ) (Figure $2 \mathrm{~b}$ ) and displays its optimal activity in the $\mathrm{pH}$ range 6-7 (Figure 2a). According to experimental results, $L d \mathrm{NDT}$ is also stable between $\mathrm{pH} 6-10$ at $50{ }^{\circ} \mathrm{C}$. These results suggest that alkaline environments ( $\left.\mathrm{pH} 8-10\right)$ could not 
inactivate the enzyme during this time period (Figure 2d). In order to explore the potential of $L d \mathrm{NDT}$ as biocatalyst, the enzymatic production of different purine 2 -deoxynucleoside analogues has been carried out.

Once operational conditions of $L d N D T$ were determined, a multienzymatic system composed by 2'-deoxyribosyltransferase from Lactobacillus delbrueckii (LdNDT) and the hypoxanthine-guanine-xanthine phosphoribosyltransferase from Thermus themophilus HB8 (TtHGXPRT) were developed. The use of coupled system $L d N D T / T t H G X P R T$ allowed for the synthesis of different therapeutical purine nucleosides, such as 2-chloro-2'-deoxyadenosine (cladribine, approved FDA drug for the treatment of hairy-cell leukemia [1], 2-fluro-2'-deoxyadenosine (a prodrug of 2-fluoroadenine, used in suicide gene therapy [1]), among others. In addition, resulting by-products from transglycosylation reaction (hypoxanthine or guanine) were transformed to added value compounds (IMP or GMP). Moreover, due to TtHXGPRT is a 6-oxopurine phosphoribosyltransferase (with a strict specificity for 6-oxopurines, such as guanine and hypoxanthine [11]), the purine base derivatives used as acceptors in transglycosylation reaction $\left(B_{2}\right)$ (Figure 1$)$ cannot be recognized by $T t$ HXGPRT. As a consequence of this, there will not undesired by-products in reaction medium.

In addition to this, the unusual tolerance to alkaline conditions of LdNDT and TtHGXPRT [11], it is a very interesting advantage for covalent immobilization of the enzyme, an essential requisite for its industrial implementation. Covalent immobilization of proteins usually occurs via multipoint attachment through the region with higher density of primary amino groups, especially with $\varepsilon-\mathrm{NH}_{2}$ from lysine residues [22]. Due to this, covalent immobilization techniques usually employ long reaction times (2-24 h) and alkaline conditions ( $\mathrm{pH} 8-10)$. In this way, the exceptional stability that is displayed by LdNDT and TtHGXPRT [11] under alkaline conditions suggests that they could be efficiently immobilized.

However, this multienzymatic approach needs to improve several features in order to be applied as industrial biocatalyst, such as the possibility to shift totally the equilibrium or the high price of PRPP. One of the most significant limitations to the practical application of this multi-enzymatic system as industrial biocatalysts is the high cost and instability of PRPP. To address these issues, several attempts to produce PRPP from non-expensive substrates will tested in a future including different PRPP sources. In addition, high concentrations of PRPP and phosphate, buffer would chelate $\mathrm{Mg}^{2+}$ from reaction medium, and affect the efficiency of TtHGXPRT. In this sense, in order to scale up this process, the conversion of reaction 2 could be improved using higher concentrations of $\mathrm{MgCl}_{2}$.

\section{Materials and Methods}

\subsection{Chemicals}

Cell culture medium reagents were from Difco (St. Louis, MO, USA). Trimethyl ammonium acetate buffer was purchased from Sigma-Aldrich (Sigma-Aldrich, Madrid, Spain). All the other reagents and organic solvents were purchased to Scharlab (Scharlab, Barcelona, Spain) and Symta (Symta, Madrid, Spain). All natural and non-natural nucleosides and bases used in this work were provided by Carbosynth Ltd. (Carbosynth Ltd., Compton, UK).

\subsection{Production and Purification of Recombinant LdNDT and TtHGXPRT}

The encoding $n d t$ gene, which codifies 2'-deoxyribosyltransferase type II from Lactobacillus delbrueckii subsp. lactis DSM 20072 (NCBI Reference Sequence: WP_002877839.1) was ordered and purchased from Genscript (Piscataway, NJ, USA). The coding sequence appeared as an NdeI-EcorI fragment was subcloned into the expression vector $\mathrm{pET} 28 \mathrm{~b}(+)$. The resultant, recombinant vector pET28bLdNDT provided an N-terminal His6-tagged fusion protein with a thrombin cleavage site between the tag and the enzyme. LdNDT was expressed in E. coli BL21(DE3) and growth in LB medium at $37^{\circ} \mathrm{C}$ with kanamycin $50 \mu \mathrm{g} / \mathrm{mL}$. Protein overexpression was induced by adding $0.5 \mathrm{mM}$ isopropyl- $\beta$-D-1-thiogalactopyranoside and the cells were further grown for $3 \mathrm{~h}$. These were harvested 
via centrifugation at $3500 \times g$. The resulting pellet was resuspended in $10 \mathrm{mM}$ sodium phosphate buffer, $\mathrm{pH}$ 7.0. Crude extracts were prepared by French press lysis of cell suspensions. The lysate was centrifuged at $17,500 \times g$ for $40 \mathrm{~min}$ and the supernatant was filtered through a $0.22 \mu \mathrm{m}$ filter (Millipore). Cleared lysate was loaded onto a 5-mL HisTrap FF column (GE Healthcare) pre-equilibrated in a binding buffer (10 mM sodium phosphate buffer, pH 7.0, with $100 \mathrm{mM} \mathrm{NaCl}$, and $10 \mathrm{mM}$ imidazole) and the column was washed. Bound proteins were eluted using a linear gradient of imidazole (from $10 \mathrm{mM}$ to $500 \mathrm{mM}$ ). After this process, fractions containing His6-tagged-LdNDT were pooled and concentrated, and N-terminal His6-tagged was removed from $L d$ NDT using thrombin to avoid precipitation of the protein. In a second step, fractions containing LdNDT were loaded onto a HiLoad 16/60 Superdex 200 prep grade column (GE Healthcare) pre-equilibrated in $25 \mathrm{mM}$ sodium phosphate buffer, $\mathrm{pH}$ 7.0. Fractions with the protein of interest identified by SDS-PAGE were pooled and the protein was dialyzed against $10 \mathrm{mM}$ sodium phosphate, $\mathrm{pH} 6.0$, and concentrated and stored at $4{ }^{\circ} \mathrm{C}$, until its use. Electrophoresis was carried out on $15 \%$ polyacrylamide slab gel with $25 \mathrm{mM}$ Tris- $\mathrm{HCl}$ buffer, $\mathrm{pH}$ 8.6, 0.1\% SDS [23]. Protein concentration was determined spectrophotometrically by UV absorption at $280 \mathrm{~nm}$ using $\varepsilon_{280}=34,380 \mathrm{M}^{-1} \mathrm{~cm}^{-1}$ [24].

TtHGXPRT was produced and purified according to experimental protocols, as previously reported [11].

\subsection{N-deoxyribosyltransferase Assay}

The standard activity assay was performed by incubating $0.3 \mu \mathrm{g}$ of pure enzyme with $10 \mathrm{mM}$ $2^{\prime}$-deoxyinosine (dIno) and $10 \mathrm{mM}$ adenine (Ade) in $50 \mathrm{mM}$ MES buffer pH 6.0 in a final volume of $40 \mu \mathrm{L}$. The reaction mixture was incubated at $40{ }^{\circ} \mathrm{C}$ for $10 \mathrm{~min}(300 \mathrm{rpm})$. Enzyme was inactivated by adding $40 \mu \mathrm{L}$ of cold methanol in ice-bath and heating for $5 \mathrm{~min}$ at $100{ }^{\circ} \mathrm{C}$. After centrifugation at $9000 \times g$ for $2 \mathrm{~min}$, the samples were half-diluted with water and frozen at $-20{ }^{\circ} \mathrm{C}$. Nucleoside production was analysed using HPLC to measure quantitatively the reaction products, as described below. All of the determinations were carried out in triplicate and the maximum error was less than $5 \%$. Under such conditions, one international activity unit (IU) was defined as the amount of enzyme producing $1 \mu \mathrm{mol} / \mathrm{min}$ of $2^{\prime}$-deoxyadenosine under the assay conditions.

\subsection{Substrate Specificity}

In order to explore the substrate specificity, $0.3 \mu \mathrm{g}$ of $L d \mathrm{NDT}$ were incubated with $10 \mathrm{mM}$ of purine and pyrimidine nucleosides and bases in $50 \mathrm{mM}$ MES buffer, $\mathrm{pH} 6.5$ in a final volume of $40 \mu \mathrm{L}$ at $50{ }^{\circ} \mathrm{C}$, and $300 \mathrm{rpm}$ orbital shaking at different reaction times. At regular times, samples were taken, and enzymatic activity was evaluated, as described in analytical methods section.

\subsection{Influence of $p H$, Temperature and Ionic Strength on Enzyme Activity}

The $\mathrm{pH}$ profile of purified recombinant enzyme was initially determined using the standard assay described above with sodium citrate ( $\mathrm{pH} 4-6)$, sodium phosphate ( $\mathrm{pH}$ 6-8). MES (6-7) and sodium borate $(\mathrm{pH} 8-10)$ as reaction buffers $(50 \mathrm{mM})$. The optimum temperature was determined using the standard assay across a $20-90{ }^{\circ} \mathrm{C}$ temperature range. The effect of ionic strength on $2^{\prime}$-deoxyribosyltransferase activity was studied by incubating $0.3 \mu \mathrm{g}$ of enzyme with different concentrations of $\mathrm{NaCl}(0$ to $1.0 \mathrm{M})$ in $50 \mathrm{mM}$ MES buffer, $\mathrm{pH} 6.0$ at $50^{\circ} \mathrm{C}$ under standard conditions described for enzymatic assay.

\subsection{Thermal and $p H$ Stability of LdNDT}

$L d \mathrm{NDT}$ was stored at $-80{ }^{\circ} \mathrm{C}$ in $10 \mathrm{mM}$ sodium phosphate, $\mathrm{pH} 7.0$ for 300 days. Samples were taken periodically and enzymatic activity was evaluated. Storage stability was defined as the relative activity between the first and successive reactions. Moreover, thermal stability of $L d \mathrm{NDT}$ was assessed by incubating $0.3 \mu \mathrm{g}$ of pure enzyme in a $\mathrm{pH}$ range from 6 to 10 , at $50^{\circ} \mathrm{C}$ for a period of $30 \mathrm{~h}$. After this, the activity was measured using standard assay. 


\subsection{Enzymatic Production of Nucleoside Analogues by Soluble LdNDT}

Enzymatic productions of non-natural nucleosides was carried out at variable amounts of enzyme, using different nucleoside and base analogues. Reactions were carried out incubating $0.3 \mu \mathrm{g}$ of $L d \mathrm{NDT}$ with $1 \mathrm{mM}$ nucleoside and base, in $50 \mathrm{mM}$ sodium phosphate buffer $\mathrm{pH} 6.0$ at $50^{\circ} \mathrm{C}$, in a final volume of $40 \mu \mathrm{L}$, with $300 \mathrm{rpm}$ orbital shaking at different reaction times (20-120 $\mathrm{min})$, and were stopped according experimental procedure described above. Enzymatic activity was evaluated, as described in analytical methods section.

\subsection{Enzymatic Production of Purine NAs and Purine NMPs Catalyzed by Multi-Enzymatic System LdNDT/TtHGXPRT}

Reaction mixtures contained $0.3 \mu \mathrm{g}$ of electrophoretically pure $L d \mathrm{NDT}, 1 \mu \mathrm{g}$ of TtHGXPRT, $3 \mathrm{mM}$ 2'-deoxynucleoside, $1 \mathrm{mM}$ nucleobase, $1 \mathrm{mM}$ 5-phospho- $\alpha$-D-ribosyl-1-pyrophosphate (5-PRPP) and $1.2 \mathrm{mM} \mathrm{MgCl}_{2}$ in $50 \mathrm{mM}$ sodium phosphate buffer, $\mathrm{pH}$ 6.0, in a final volume of $40 \mu \mathrm{L}$. Reactions were conducted at $50{ }^{\circ} \mathrm{C}$ with shaking (300 rpm) at different reaction times (20-120 min), and were stopped according experimental procedure described above. Enzymatic activity was evaluated, as described in analytical methods section.

\subsection{Analytical Methods}

\subsubsection{Analytical Methods for $L d N D T$}

The production of nucleosides was quantitatively measured with an ACE $5 \mu \mathrm{m}$ C18-PFP column $250 \mathrm{~mm} \times 46 \mathrm{~mm}$ (Symta, Madrid, Spain) pre-equilibrated in 100\% trimethyl ammonium acetate. Elution was carried out at a flow rate of $0.9 \mathrm{~mL} / \mathrm{min}$, by a discontinuous gradient: $0-10 \mathrm{~min}, 100 \%$ to $90 \%$ trimethyl ammonium acetate and $0 \%$ to $10 \%$ acetonitrile, and $10-20 \mathrm{~min}, 90 \%$ to $100 \%$ trimethyl ammonium acetate and $10 \%$ to $0 \%$ acetonitrile. The nucleoside product was eluted into the diode array detector for quantification at 230, 240, 254, and $260 \mathrm{~nm}$.

Retention times for the reference natural and non-natural bases (hereafter abbreviated according to the recommendations of the IUPAC-IUB Commission on Biochemical Nomenclature) were as follows: adenine (Ade), $10.2 \mathrm{~min}$; guanine (Gua), $7.3 \mathrm{~min}$; hypoxanthine (Hyp), $7.5 \mathrm{~min}$; benzimidazole (B), $29.6 \mathrm{~min}$; 2,6-diaminopurine (2,6-DAP), $11.1 \mathrm{~min}$; 6-mercaptopurine (6-M), $10.5 \mathrm{~min}$; 6-methylpurine (6-MetPur): $13.8 \mathrm{~min}$; 2-fluoroadenine (2-FAde), $14.4 \mathrm{~min}$; 6-benzoyladenine (6-BenzoAde), 16.6; 2-chloroadenine (2-ClAde), $17.3 \mathrm{~min}$; 6-chloropurine (6-ClPur), $16.7 \mathrm{~min}$; 6-methoxyguanine (6-MeOGua), $16.4 \mathrm{~min}$; 7-deaza-6-hydroxypurine (7-deaza6OHPur), $9.0 \mathrm{~min}$; 7-deazaxanthine (7-deazaXan), $8.5 \mathrm{~min}$; theophylline (The), $20.0 \mathrm{~min}$; benzoyladenine (BenzoA); $22 \mathrm{~min}$; and, xanthine (Xan), $8 \mathrm{~min}$.

Retention times for the nucleosides (hereafter abbreviated according to the recommendations of the IUPAC-IUB Commission on Biochemical Nomenclature) were as follows: 2'-deoxyadenosine (dAdo), $15.5 \mathrm{~min} ; 2^{\prime}$-deoxyguanosine (dGuo), $11.6 \mathrm{~min}$; 2'-deoxyinosine (dIno), $12.0 \mathrm{~min}$; 33.5; 2,6-diaminopurine-2'-deoxyribose (2,6-DAPdRib), $16.0 \mathrm{~min}$; 6-mercaptopurine-2'-deoxyribose (6-MdRib), $13.5 \mathrm{~min}$; 6-methylpurine-2'-deoxyribose (6-MetPurdRib), $17.7 \mathrm{~min}$; 2-fluoro-2' -deoxyadenosine (2-F-dAdo), $19.0 \mathrm{~min}, 2$-chloro-2' ${ }^{\prime}$-deoxyadenosine (2-CldAdo), $23.2 \mathrm{~min}$; 6-chloropurine-2'-deoxyribose (6-ClPurdRib), $22.9 \mathrm{~min}$; 6-methoxy-2'-deoxyguanosine (6-MeOdGuo), $21.8 \mathrm{~min}$; 7-deaza-6-hydroxypurine-2'-deoxyribose (7-deaza6OHPurdRib), $14.0 \mathrm{~min}$; 7-deazaxanthine-2'-deoxyribose (7-deazadXao), $13.5 \mathrm{~min}$; theophylline-2'-deoxyribose (ThedRib), $27.0 \mathrm{~min}$; benzoyladenine-2'-deoxyribose (BenzoAdRib); $29.0 \mathrm{~min}$; and, 2'-deoxyxanthosine (dXao), $13.0 \mathrm{~min}$. The identification and quantification of most of reaction substrates and products have been performed in relation to external standards using the above, well characterized commercial products. In the case of 7-deaza-6-hydroxypurine-2'-deoxyribose, 7-deazaxanthine-2'-deoxyribose, theophylline- $2^{\prime}$-deoxyribose, and benzoyladenine-2' -deoxyribose we use the decrease of corresponding starting nucleobases to quantify the formation of products. 


\subsubsection{Analytical Methods for Multi-Enzymatic System $L d$ NDT/TtHGXPRT}

The production of 2'-deoxynucleosides and nucleoside-5'-monophosphates was quantitatively measured with an ACE EXCEL $5 \mu \mathrm{m}$ CN-ES column $250 \mathrm{~mm} \times 4.6 \mathrm{~mm}$ (Symta, Madrid, Spain) equilibrated with $100 \%$ trimethyl ammonium acetate at a flow rate of $0.8 \mathrm{~mL} / \mathrm{min}$. The nucleoside product was eluted into the diode array detector for quantification at 230, 240, 254, and $260 \mathrm{~nm}$.

Retention times for the reference natural and non-natural bases (hereafter abbreviated according to the recommendations of the IUPAC-IUB Commission on Biochemical Nomenclature) were as follows: adenine (Ade), $10.2 \mathrm{~min}$; guanine (Gua), $5.8 \mathrm{~min}$; hypoxanthine (Hyp), $5.3 \mathrm{~min}$; 2,6-diaminopurine (2,6-DAP), $9.5 \mathrm{~min}$; 6-mercaptopurine (6-M), $7.8 \mathrm{~min}$; 6-methylpurine (6-MetPur): $14.5 \mathrm{~min}$; 2-fluoroadenine (2-FAde), $14.4 \mathrm{~min}$; 2-chloroadenine (2-ClAde), $25.0 \mathrm{~min}$; and, 6-methoxyguanine (6-MeOGua), 19.4 min.

Retention times for the nucleosides (hereafter abbreviated according to the recommendations of the IUPAC-IUB Commission on Biochemical Nomenclature) were as follows: 2'-deoxyadenosine (dAdo), $19.5 \mathrm{~min} ; 2^{\prime}$-deoxyguanosine (dGuo), $10.2 \mathrm{~min}$; 2'-deoxyinosine (dIno), $9.0 \mathrm{~min}$; 33.5; 2,6-diaminopurine-2'-deoxyribose (2,6-DAPdRib), $20.1 \mathrm{~min}$; 6-mercaptopurine-2'-deoxyribose (6-MdRib), $11.5 \mathrm{~min}$; 6-methylpurine-2'-deoxyribose (6-MetPurdRib), $33.4 \mathrm{~min}$; 2-fluoro-2'-deoxyadenosine (2-F-dAdo), $34.0 \mathrm{~min}, 2$-chloro-2'-deoxyadenosine (2-CldAdo), $65.0 \mathrm{~min}$; and, 6-methoxy-2'-deoxyguanosine (6-MeOdGuo), $27.8 \mathrm{~min}$.

Retention times for the nucleosides-5'-monophosphate (hereafter abbreviated according to the recommendations of the IUPAC-IUB Commission on Biochemical Nomenclature) were as follows: guanosine-5'-monophosphate (5'-GMP), 3.1 min; inosine-5' - monophosphate (5'-IMP), 3.4 min.

The identification and quantification of most of reaction substrates and products have been performed in relation to external standards using the above, well characterized commercial products.

\section{Conclusions}

In conclusion, the use of multi-enzymatic system $L d N D T / T t H G X P R T$ for the synthesis of purine NAs and purine NMPs could be a very interesting methodology for industrial synthesis of nucleic acid derivatives. In addition, the use of $L d N D T / T t H G X P R T$ would offer the possibility to transform resulting by-products in high-value compounds and shift the equilibrium reaction of transglycosylation reaction in desired way. Despite several drawbacks need to be improved, such as the high price of PRPP, the total displacement of reaction equilibrium, or the costs of the purification of NMPS and NAs, the high price of some of these therapeutic nucleosides, and the sustainability of this process are good reasons to deepen into this novel bioprocess.

Supplementary Materials: The following are available online at www.mdpi.com/2073-4344/8/1/9/s1, Table S1: Effect of molar ratio in the production of purine NAs catalyzed by $L d$ NDT or LdNDT/TtHGXPRT.

Acknowledgments: This work was supported by grant SAN151610 from the Santander Foundation. Grant 2016/UEM08 from European University of Madrid is also acknowledged.

Author Contributions: J.F.-L. conceived and designed the experiments. J.A., J.d.A., S.M.-P., V.J.C.-S. and J.F.-L. contributed to the development and analysis of experimental data.

Conflicts of Interest: The authors declare no conflict of interest.

\section{References}

1. Parker, W.B. Enzymology of purine and pyrimidine antimetabolites used in the treatment of cancer. Chem. Rev. 2009, 109, 2880-2893. [CrossRef] [PubMed]

2. De Clercq, E. Recent highlights in the development of new antiviral drugs. Curr. Opin. Microbiol. 2005, 8, 552-560. [CrossRef] [PubMed]

3. Behrens, M.; Meyerhof, W.; Hellfritsch, C.; Hofmann, T. Sweet and umami taste: Natural products, their chemosensory targets, and beyond. Angew. Chem. Int. Ed. 2011, 50, 2220-2242. [CrossRef] [PubMed] 
4. Mikhailopulo, I.A. Biotechnology of nucleic acid constituents-State of the art and perspectives. Curr. Org. Chem. 2007, 11, 317-335. [CrossRef]

5. Fresco-Taboada, A.; de la Mata, I.; Arroyo, M.; Fernández-Lucas, J. New insights on nucleoside 2'-deoxyribosyltransferases: A versatile biocatalyst for one-pot one-step synthesis of nucleoside analogs. Appl. Microbiol. Biotechnol. 2013, 97, 3773-3785. [CrossRef] [PubMed]

6. Lapponi, M.J.; Rivero, C.W.; Zinni, M.A.; Britos, C.N.; Trelles, J.A. New developments in nucleoside analogues biosynthesis: A review. J. Mol. Catal. B Enzym. 2016, 133, 218-233. [CrossRef]

7. Del Arco, J.; Fernández-Lucas, J. Purine and Pyrimidine Phosphoribosytransferases: A versatile tool for enzymatic synthesis of nucleoside-5'-monophosphates. Curr. Pharm. Des. 2017, 23. [CrossRef]

8. Lewkowicz, E.S.; Iribarren, A.M. Nucleoside phosphorylases. Curr. Org. Chem. 2006, 10, 1197-1215. [CrossRef]

9. Del Arco, J.; Acosta, J.; Pereira, H.M.; Perona, A.; Lokanath, N.K.; Kunishima, N.; Fernández-Lucas, J. Enzymatic production of non-natural nucleoside-5'-monophosphates by a novel thermostable uracil phosphoribosyltransferase. Chem CatChem 2017. [CrossRef]

10. Del Arco, J.; Martinez, M.; Donday, M.; Clemente-Suarez, V.J.; Fernández-Lucas, J. Cloning, expression and biochemical characterization of xanthine and adenine phosphoribosyltransferases from Thermus thermophilus HB8. Biocatal. Biotransfor. 2017, 1-8. [CrossRef]

11. Del Arco, J.; Cejudo-Sanches, J.; Esteban, I.; Clemente-Suarez, V.J.; Hormigo-Cisneros, D.; Perona, A.; Fernández-Lucas, J. Enzymatic production of dietary nucleotides from low-soluble purine bases by an efficient, thermostable and alkali-tolerant biocatalyst. Food Chem. 2017, 237, 605-611. [CrossRef] [PubMed]

12. Serra, I.; Conti, S.; Piškur, J.; Clausen, A.R.; Munch-Petersen, B.; Terreni, M.; Ubiali, D. Immobilized Drosophila melanogaster deoxyribonucleoside kinase $(D m \mathrm{dNK})$ as a high performing biocatalyst for the synthesis of purine arabinonucleotides. Adv. Synth. Catal. 2014, 356, 563-570. [CrossRef]

13. Fernández-Lucas, J. Multienzymatic synthesis of nucleic acid derivatives: A general perspective. Appl. Microbiol. Biotechnol. 2015, 99, 4615-4627. [CrossRef] [PubMed]

14. Zou, Z.; Ding, Q.; Ou, L.; Yan, B. Efficient production of deoxynucleoside-5'-monophosphates using deoxynucleoside kinase coupled with a GTP-regeneration system. Appl. Microbiol. Biotechnol. 2013, 97, 9389-9395. [CrossRef] [PubMed]

15. Mori, H.; Iida, A.; Fujio, T.; Teshiba, S. A novel process of inosine $5^{\prime}$-monophosphate production using overexpressed guanosine/inosine kinase. Appl. Microbiol. Biotechnol. 1997, 48, 693-698. [CrossRef] [PubMed]

16. Zhou, X.; Szeker, K.; Janocha, B.; Böhme, T.; Albrecht, D.; Mikhailopulo, I.A.; Neubauer, P. Recombinant purine nucleoside phosphorylases from thermophiles: Preparation, properties and activity towards purine and pyrimidine nucleosides. FEBS J. 2013, 280, 1475-1490. [CrossRef] [PubMed]

17. Iglesias, L.E.; Lewkowicz, E.S.; Medici, R.; Bianchi, P.; Iribarren, A.M. Biocatalytic approaches applied to the synthesis of nucleoside prodrugs. Biotechnol. Adv. 2015, 33, 412-434. [CrossRef] [PubMed]

18. Fernández-Lucas, J.; Acebal, C.; Sinisterra, J.V.; Arroyo, M.; de la Mata, I. Lactobacillus reuteri 2'-deoxyribosyltransferase, a novel biocatalyst for tailoring of nucleosides. Appl. Environ. Microbiol. 2010, 76, 1462-1470. [CrossRef] [PubMed]

19. Crespo, N.; Sánchez-Murcia, P.A.; Gago, F.; Cejudo-Sanches, J.; Galmes, M.A.; Fernández-Lucas, J.; Mancheño, J.M. 2'-Deoxyribosyltransferase from Leishmania mexicana, an efficient biocatalyst for one-pot, one-step synthesis of nucleosides from poorly soluble purine bases. Appl. Microbiol. Biotechnol. 2017, 101, 7187-7200. [CrossRef] [PubMed]

20. Fresco-Taboada, A.; Serra, I.; Arroyo, M.; Fernández-Lucas, J.; de la Mata, I.; Terreni, M. Development of an immobilized biocatalyst based on Bacillus psychrosaccharolyticus NDT for the preparative synthesis of trifluridine and decytabine. Catal. Today 2016, 259, 197-204. [CrossRef]

21. De Clercq, E. Highlights in the discovery of antiviral drugs: A personal retrospective. J. Med. Chem. 2010, 53, 1438-1450. [CrossRef] [PubMed]

22. Mateo, C.; Palomo, J.M.; Fernandez-Lorente, G.; Guisan, J.M.; Fernandez-Lafuente, R. Improvement of enzyme activity, stability and selectivity via immobilization techniques. Enzym. Microb. Technol. 2007, 40, 1451-1463. [CrossRef] 
23. Laemmli, U.K. Cleavage of structural proteins during the assembly of the head of bacteriophage T4. Nature 1970, 227, 680-685. [CrossRef] [PubMed]

24. Gill, S.C.; Von Hippel, P.H. Calculation of protein extinction coefficients from amino acid sequence data. Anal. Biochem. 1989, 182, 319-326. [CrossRef]

(C) 2018 by the authors. Licensee MDPI, Basel, Switzerland. This article is an open access article distributed under the terms and conditions of the Creative Commons Attribution (CC BY) license (http:/ / creativecommons.org/licenses/by/4.0/). 